\title{
Paget disease of bone among hospitalized patients in Poland
}

\author{
Krzysztof Kanecki ${ }^{1, A-F}$, Aneta Nitsch-Osuch ${ }^{1, A, C, E-F}$, Paweł Goryński ${ }^{2, A-C, E-F}$, Magdalena Bogdan ${ }^{1, A, C, E-F}$, \\ Patryk Tarka, ${ }^{1, A, C, E-F}$, Piotr Zbigniew Tyszko ${ }^{3, A-C, E-F}$ \\ ${ }^{1}$ Department of Social Medicine and Public Health, Medical University of Warsaw, Warsaw, Poland \\ ${ }^{2}$ National Institute of Public Health - National Institute of Hygiene, Warsaw, Poland \\ ${ }^{3}$ Witold Chodźko Institute of Rural Health in Lublin, Poland \\ A - Research concept and design, B - Collection and/or assembly of data, C - Data analysis and interpretation, \\ $D$ - Writing the article, E - Critical revision of the article, F - Final approval of article
}

Kanecki K, Nitsch-Osuch A, Goryński P, Bogdan M, Tarka P, Tyszko P Z. Paget disease of bone among hospitalized patients in Poland. Ann Agric Environ Med. 2018; 25(1): 182-185. doi: 10.26444/aaem/81080

\begin{abstract}
Introduction. Paget's disease (PDB) is a focal disorder of bone remodeling that occurs commonly in older people with decreasing prevalence reported in European countries. This disease is most often asymptomatic, but it can cause a variety of medical complications resulting in considerable morbidity and reduced quality of life. There is little information regarding the epidemiology of PDB in Poland. To the best of the authors' knowledge, this is the first large epidemiological analysis of this disease in Poland.

Objective. The aim of this study was to analyze factors that may be related to the PDB epidemiology among hospitalized patients in Poland.

Materials and method. The analysis was conducted on the basis of population-based administrative data, taken from a Polish hospital morbidity study carried out by the National Institute of Public Health between January 2008 - December 2014.

Results. Analyzed data covered 662 hospitalization records. The final study sample comprised $94(41.8 \%)$ male and 131 (58.2\%) female patients with first-time hospitalizations for PDB, with a significant predominance of females $(P<0.02)$, and the predominance of patients living in urban (73\%) than in rural areas $(27 \%), P<0.001$. The average age of the sample was 56.8 years ( $\mathrm{Cl}: 54.3-59.3$; SD 18.8; range 1-93 years). The number of PDB cases hospitalized in Poland significantly decreased during the analyzed period of time.

Conclusions: PDB is a rare disease with decreasing trends observed among hospitalized patients in Poland. The study results may suggest the existence of environmental risk factors for the development of PDB.
\end{abstract}

\section{Iey words}

Paget's disease of bone, hospitalization, rural population, urban population, risk factors.

\section{INTRODUCTION}

Paget's disease of bone $(\mathrm{PDB})$ is a focal disorder of bone remodeling that occurs commonly in older people. PDB is the second most common metabolic bone disease after osteoporosis. The disease is characterized by focal areas of abnormal bone remodeling which can lead to bone deformity, osteoarthritis, bone pain, pathologic fractures, deafness and nerve compression syndromes [1]. PDB is most often asymptomatic, but it can cause a variety of medical complications resulting in considerable morbidity and reduced quality of life [2]. In a recent systematic review, bone pain was the most common complaint occurring in about $40 \%$ of cases, followed by deformity (20\%), pathological fracture (10\%), and deafness (6\%) [3]. PDB is widely observed in nations with a large Anglo Saxon population $[1,4]$. The majority of PDB patients remain asymptomatic and do not require treatment $[5,6]$. Some asymptomatic patients may benefit from treatment, especially when the disease is quite active or when the bones involved are close to vital organs or bones in which the progression of the disease

Address for correspondence: Krzysztof Kanecki, Department of Social Medicine and Public Health, Medical University of Warsaw, Warsaw, Poland

E-mail: kanecki@mp.pl

Received: 19.07.2017; accepted: 08.12.2017; first published: 12.02.2018 may lead to complications [5-7]. Patients with significant symptoms should also be treated $[5,8]$. Second-generation bisphosphonates are widely regarded as the treatment of this disease [9].

Epidemiology. The prevalence rate of PDB in New Zealand is believed to be among the highest in the world [4]. In the United Kingdom, PDB was reported to be a rare disease in subjects under 50 years of age, but it increased in prevalence progressively thereafter to affect $5.8 \%$ of women and $6.9 \%$ of men aged over 85 . The overall prevalence in those above the age of 55 in the UK was about $2 \%$ [1]. The prevalence of Paget's disease in elderly French women is similar to that recently reported in the UK [10]. PDB in Italy has an estimated prevalence rate ranging from $0.7 \%$ (radiological studies) - 2.4\% (bone scan study) [11]. Prevalence of PDB in Spain amounts to at least $1 \%$ in individuals older than 55 , with remarkable geographical variations and age-related differences [12]. In non-European countries, the PDB prevalence is lower than in European countries and varies widely. The total prevalence was 6.8 per 1,000 patients, and the incidence density for PDB at 50.3 per 10,000 person-years in Recife in South America [13]. In the USA, approximately $1-2 \%$ of the population are affected by PDB, with the northeastern region showing the highest prevalence [14]. The 
prevalence rate of PDB was reported to be low in Japan $(0.00028 \%)[15]$ and is believed to be a rare disease in Asia $[16,17]$.

Genetic, environmental and other factors related to PDB. The cause of PDB is unknown, but genetic factors, particularly SQSTM1 mutations, and a substantial gene-environment interaction may be related to PDB [18]. Until now, SQSTM1 is the only PDB-causing gene identified. However, PDB patients without SQSTM1 mutations seem to have susceptibility to genetic polymorphisms in regions containing CaSR, ESR1, TNFRSF11B (OPG), TNFRSF11A (RANK), CSF1 (M-CSF), OPTN, TM7SF4 (DC-STAMP), VCP, NUP205, RIN3, PML, and GOLGA6A genes, which results in an increased risk of developing PDB [19].

Genetic factors seem to be important. Mutations in SQSTM1 occur in 25-50\% of familial PD. Genotypephenotype relationships are present, as PD develops at an earlier age and is more extensive and severe in those with SQSTM1 mutations. These findings are more pronounced in those with truncating mutations [20].

Age and gender are the principal factors that have previously been related to the prevalence of PDB which increases substantially with age [12, 21-24]. Patients were diagnosed with Paget's disease of bone for the first time at the mean age of 69.6 years [22]. The disease was higher in frequency in people who were in the older decades of life with the highest prevalence of $2.32+0.54 \%$ in the $65-74$-yearold age group [14]. It has been reported that the rate of PDB may increase significantly in those over 80 years of age [25]. Men were reported to be more frequently affected [21, 25-26]. Urban vs. rural residence may also be related to the prevalence of PDB, with more cases in urban centres of population [22]. PDB is reported to be significantly associated with wood-fired heating in childhood and/or adolescence [27]. The prevalence of PDB in archeological population groups was studied through the examination of skeletons available from central Europe, and these studies showed prevalence in central Europe (0.03\%) [28].

PDB trends in recent years. Prevalence of Paget's disease in New Zealand has declined over the past two decades, indicating that there are important environmental determinants in its development [4]. No secular trend for decreasing prevalence of PDB in Italy was observed [23]. Previous studies indicated a reduction in the prevalence of Paget disease [29-30]. Another large study in England and Wales estimated that the prevalence of this disorder was $0.3 \%$ in subjects over 55 years of age [1]. In addition, a decrease in the prevalence of Paget's disease has been noticed in some European countries over a 20 -year period, reaching an overall rate of $0.3 \%$ [21]. Moreover, the annual incidence of new cases of PDB has declined significantly in USA over the past 20 years [22]. A recent study demonstrated that the incidence of PDB in Spain had remained stable over the past 24 years in one region, substantial changes had been observed in the other region, although the severity of the disease had declined [31]. It was reported that the secular trend of Paget's disease present later in life and in a milder form may be related to important environmental determinants. Given the secular trend and limitations to life expectancy, it is predicted that Paget's disease will become increasingly rare [25].

\section{OBJECTIVES}

Most epidemiological studies on PDB have been performed in the UK and in other populations of British descent, such as those in the USA, Australia, and New Zealand. In contrast, few data are available about the epidemiology and characteristics of PDB in other European populations. Despite the impact of the disease on the population, only limited information about the epidemiology of PDB in Poland is available. The purpose of this study was to analyze factors that may be related to the PDB epidemiology among hospitalized patients in Poland.

\section{MATERIALS AND METHOD}

The analysis was performed using population-based administrative data collected between January 2008 December 2014 by the National Institute of Public Health, as a part of the Polish Hospital Morbidity Study. Data on all inpatients discharged (living or deceased) from all hospitals, excluding psychiatric and military hospitals, are reported to the Institute, usually on a monthly basis. The database contains information from hospital documentation about each hospitalization, including the ICD-10 codes of the admission diagnosis and comorbidities, dates of admission and discharge, and the patient's birth date, gender, and place of residence. The database does not contain patients' names. Two analytic samples were considered in the current study: 1 ) all hospitalizations for PDB, and 2) first-time hospitalization for PDB. In addition to data from the hospital morbidity study, demographic data for the general Polish population were obtained from the Polish Central Statistical Office [32]. Incidence and prevalence rates were calculated using the number of PDB patients and corresponding census data. One study used a large primary care record-linkage resource, the General Practice Research Database (GPRD), to evaluate the incidence, clinical presentation, and natural history of Paget's disease of bone in England and Wales [1]. In another study, PDB prevalence was estimated on the basis of inpatient data in Italy [23] and Spain [12]. In Poland, a good alternative for an analysis of PDB epidemiology may be the database of the National Institute of Public Health.

Statistical analysis. All statistical analyses were performed using a licensed version of Statistica Software Dell Inc. (2016). Dell Statistica (data analysis software system), version 13. software.dell.com.) and WINPEPI programmes [33]. The results of descriptive analyses were expressed as means, medians and ranges for continuous variables, as well as counts and percentages for categorical data. 95\% CIs were calculated assuming Poisson distributions of the observed cases. Nonparametric tests were used as appropriate when normality assumptions were not met. The chi-squared test was used to determine whether there was a significant difference between the frequencies. The linear regression analysis was used for trend analysis. A $P$-value of $<0.05$ was considered to be statistically significant. 


\section{RESULTS}

Analyzed data covered 662 hospitalization records. The final study sample comprised 94 (41.8\%) male and 131 (58.2\%) female patients with first-time hospitalizations for PDB, with a significant predominance of females $(P<0.02)$, and a predominance of patients living in more urban $(73 \%)$ than rural areas $(27 \%), P<0.001$. The average age of the sample was 56.8 years (CI: $54.3-59.3$; SD 18.8; range $1-93$ years). The incidence of Paget's disease is difficult to estimate because most patients are asymptomatic. Based on hospitalization registers, the average incidence of $\mathrm{PDB}$ among hospitalized patients may be estimated at 0.8 / million per year $(95 \% \mathrm{CI}$ : $0.6-1)$. The actual incidence is probably at least several times higher since PDB is largely asymptomatic. The number of newly-diagnosed cases of PDB in Poland per year across the study period by gender is presented in Figure 1, and by place of residence in Figure 2. The number of first-time hospitalizations of PDB patients decreased significantly in the analyzed period of time $(P<0.05)$.

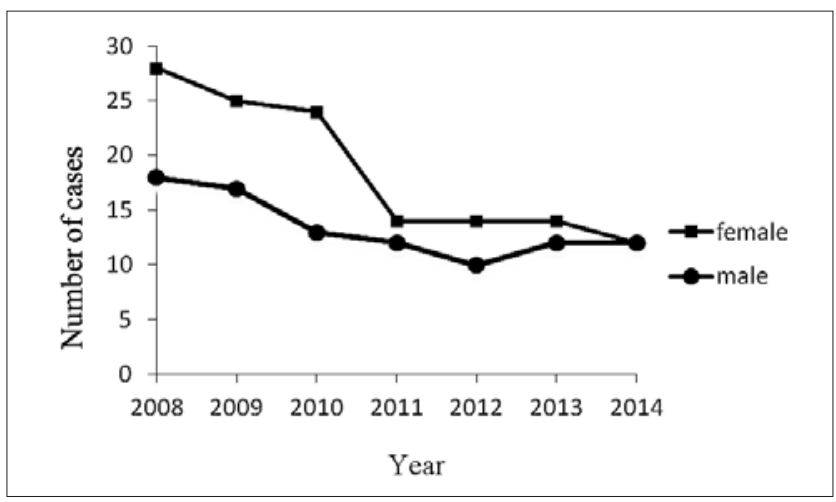

Figure 1. Number of cases of Paget's disease of bone by gender per year in Poland, 2008-2014

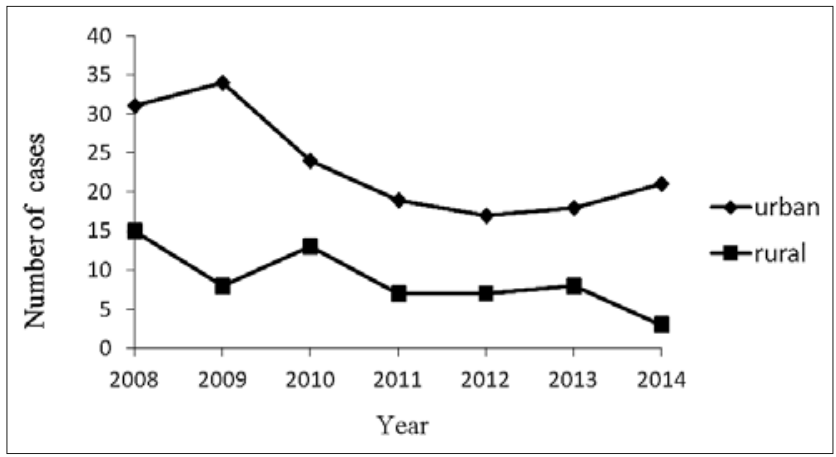

Figure 2. Number of cases of Paget's disease of bone by place of residence per year in Poland, 2008-2014

\section{DISCUSSION}

Although epidemiologic data on the PDB epidemiology have been reported in several European countries, there is no comprehensive analysis of the PDB epidemiology and factors related to this disease in Poland. Because PDB may be asymptomatic, it is difficult to assess the PDB incidence, but it is expected that the analysis of hospitalization data from a 7-year period of time may provide approximate information on the incidence of $\mathrm{PDB}$ in patients requiring hospitalization.
On the basis of the data obtained from a national inpatient discharge database, the average annual incidence of PDB in Poland may be estimated at 0.8 per million, which may be lower than the incidence reported in other European countries. The reason may be related to the fact that PDB is often asymptomatic and is frequently discovered incidentally when an elevated serum alkaline phosphatase is found in a routine laboratory test, or discovered radiographically in an x-ray performed for unrelated reasons. PDB can be diagnosed in outpatient care, but hospitalization may be considered necessary when the following symptoms appear: bone fractures or deformities, bone changes deteriorating quickly, unspecified pain, deafness, elevated calcium levels, heart failure, paraplegia or spinal stenosis.

PDB affects mainly elderly people, who may be hospitalized more often than those who are younger. A recent populationbased study from Olmsted County, Minnesota, USA, found that $58 \%$ of the patients had symptoms at diagnosis [34]. On the basis of this information, it can be assumed that the PDB incidence rate is several times higher than the incidence calculated in this study.

The number of hospitalization cases in PDB patients in Poland decreased significantly in 2008-2014. The decline in both the prevalence and the severity of PDB has been documented in other countries in the recent past $[21,35$, 36]. The incidence and prevalence rates of PDB vary widely between populations, but both have decreased in most regions in recent years [37]. At present, the reasons for these changes remain unclear, but they are likely to be due to an interaction between genetic factors and environmental triggers which may differ in different regions [37]. Additionally, the geographical distribution of PDB has been shown to differ not only between different countries, but also within the same country. Areas of remarkably high prevalence have been described in the northeast of the USA, and territories of Spain and Italy $[14,38,39]$. The average age of people with PDB ranged from 50-60 years and it is similar to data from other European countries. It was reported in another study that there was a secular trend of Paget's disease presenting later in life and in a milder form, which might be related to environmental determinants [25]. In this study, PDB was more significantly observed in females than males. This observation may be associated with an increased risk of PDB in females, or the existence of environmental or other unknown factors that increase the risk of PDB in females.

Data from this study suggest that an unknown environmental factor may be related to the higher PDB incidence in urban that rural areas. While environmental pollution affects mainly urban areas, its progressive reduction can decrease the frequency of PDB occurrence in Poland in both genders, as observed in the presented study and illustrated in Figure 1. In another study, more PDB cases were also observed in urban than rural areas [22]. Other environmental triggers suggested to be implicated include less exposure to zoonoses due to emigration from rural to urban areas, and fewer infections due to public health measures and vaccination programmes [37]. PDB appeared to be more prevalent in rural than in urban areas of Italy, and a significant association with animal contacts was shown, providing further support for the role of infective agents [11]. Additionally, animal-related factors may be important in the etiology of PDB and may interact with SQSTM1 mutations, thus influencing the disease severity [40]. It was reported that 
the decreasing incidence of Paget's disease, which could be attributed to measles vaccination, supports an etiologic role of the virus [41]. However, RNA of the measles virus was not found in the bone marrow and bone cell cultures isolated from patients with Paget's disease in New Zealand [42].

\section{CONCLUSIONS}

The epidemiology of PD appears to have been changing recently, with several groups in different parts of the world reporting a marked reduction in the prevalence and incidence of PBD. PDB is rarely seen in Poland, with a decreasing incidence in recent years. These findings seem most likely to be caused by changes in the exposure to unknown environmental factors, or the existence of a genetic predisposition, or both. However, while significant progress has been made in the identification of the genetic mutations associated with PDB, further research is needed to determine the environmental factors involved.

\section{REFERENCES}

1. van Staa TP, Selby P, Leufkens HG, Lyles K, Sprafka JM, Cooper C. Incidence and natural history of Paget's disease of bone in England and Wales. J Bone Miner Res. 2002; 17(3): 465-471.

2. Gold DT, Boisture J, Shipp KM, Pieper CF, Lyles KW. Paget's disease of bone and quality of life. J Bone Miner Res. 1996; 11(12): 1897-1904.

3. Tan A, Ralston SH. Clinical presentation of Paget's disease: evaluation of a contemporary cohort and systematic review. Calcif Tissue Int. 2014; 95(5): 385-392.

4. Doyle T, Gunn J, Anderson G, Gill M, Cundy T. Paget's disease in New Zealand: evidence for declining prevalence. Bone. 2002; 31(5): 616-619.

5. Selby PL. Guidelines for the diagnosis and management of Paget's disease: a UK perspective. J Bone Miner Res. 2006; 21 Suppl 2: 92-93.

6. Takata S, Hashimoto J, Nakatsuka K, Yoshimura N, Yoh K, Ohno I, et al. Guidelines for diagnosis and management of Paget's disease of bone in Japan. J Bone Metab. 2006; 24(5): 359-367.

7. Whyte MP. Clinical practice. Paget's disease of bone. N Engl J Med. 2006; 355(6): 593-600.

8. Devogelaer JP, Bergmann P, Body JJ, Boutsen Y, Goemaere S, Kaufman $\mathrm{JM}$, et al. Management of patients with Paget's disease: a consensus document of the Belgian Bone Club. Osteoporos Int: 2008; 19(8):11091117.

9. Langston AL, Campbell MK, Fraser WD, MacLennan GS, Selby PL, Ralston SH. Randomized trial of intensive bisphosphonate treatment versus symptomatic management in Paget's disease of bone. J Bone Miner Res. 2010; 25(1): 20-31.

10. Lecuyer N, Grados F, Dargent-Molina P, Deramond H, Meunier PJ, Fardellone P. Prevalence of Paget's disease of bone and spinal hemangioma in French women older than 75 years: data from the EPIDOS study. Joint Bone Spine. 2000; 67(4): 315-318.

11. Gennari L, Merlotti D, Martini G, Nuti R. Paget's disease of bone in Italy. J Bone Miner Res. 2006; 21 Suppl 2: 14-21.

12. Guanabens N, Garrido J, Gobbo M, Piga AM, del Pino J, Torrijos A, et al. Prevalence of Paget's disease of bone in Spain. Bone. 2008; 43(6): 1006-1009.

13. Reis RL, Poncell MF, Diniz ET, Bandeira F. Epidemiology of Paget's disease of bone in the city of Recife, Brazil. Rheumatol Int. 2012; 32(10): 3087-3091.

14. Altman RD, Bloch DA, Hochberg MC, Murphy WA. Prevalence of pelvic Paget's disease of bone in the United States. J Bone Miner Res. 2000; 15(3): 461-465.

15. Hashimoto J, Ohno I, Nakatsuka K, Yoshimura N, Takata S, Zamma $\mathrm{M}$, et al. Prevalence and clinical features of Paget's disease of bone in Japan. J Bone Miner Metab. 2006; 24(3): 186-190.

16. Sirikulchayanonta V, Jaovisidha S, Subhadrabandhu T, Rajatanavin R. Asymptomatic Paget's bone disease in ethnic Thais: a series of four case reports and a review of the literature. J Bone Miner Metab. 2012; 30(4): 485-492.
17. Wat WZ, Cheung WS, Lau TW. A case series of Paget's disease of bone in Chinese. Hong Kong Med J. 2013; 19(3): 242-248.

18. Cundy T, Rutland MD, Naot D, Bolland M. Evolution of Paget's disease of bone in adults inheriting SQSTM1 mutations. Clin Endocrinol. 2015; 83(3): 315-319.

19. Chung PY, Van Hul W. Paget's disease of bone: evidence for complex pathogenetic interactions. Semin Arthritis Rheum. 2012; 41(5): 619641.

20. Bolland MJ, Cundy T. Republished: Paget's disease of bone: clinical review and update. Postgrad Med J. 2014; 90(1064): 328-331.

21. Poor G, Donath J, Fornet B, Cooper C. Epidemiology of Paget's disease in Europe: the prevalence is decreasing. J Bone Miner Res. 2006; 21(10): 1545-1549.

22. Tiegs RD, Lohse CM, Wollan PC, Melton LJ. Long-term trends in the incidence of Paget's disease of bone. Bone. 2000; 27(3): 423-427.

23. Gennari L, Di Stefano M, Merlotti D, Giordano N, Martini G, Tamone $\mathrm{C}$, et al. Prevalence of Paget's disease of bone in Italy. J Bone Miner Res. 2005; 20(10): 1845-1850.

24. Eekhoff ME, van der Klift M, Kroon HM, Cooper C, Hofman A, Pols HA, et al. Paget's disease of bone in The Netherlands: a populationbased radiological and biochemical survey--the Rotterdam Study. J Bone Miner Res. 2004; 19(4): 566-570.

25. Bastin S, Bird H, Gamble G, Cundy T. Paget's disease of bone--becoming a rarity? Rheumatology (Oxford). 2009; 48(10): 1232-1235.

26. Gennari L, Merlotti D, Martini G, Nuti R. Paget's Disease of Bone in Italy. J Bone Miner Res. 2006; 21(S2): 14-21.

27. Audet MC, Jean S, Beaudoin C, Guay-Belanger S, Dumont J, Brown JP, et al. Environmental factors associated with familial or non-familial forms of Paget's disease of bone. Joint Bone Spine. 2016 Dec 6. DOI: 10.1016/j.jbspin.2016.11.010. [Epub ahead of print]

28. Pusch CM, Czarnetzki A. Archaeology and prevalence of Paget's disease. J Bine Miner Res. 2005; 20(8):1484; author reply 1485. Epub 2005 May 2.

29. Cundy T. Is Paget's disease of bone disappearing? Skeletal Radiol. 2006; 35(6): 350-351.

30. Cooper C, Schafheutle K, Dennison E, Kellingray S, Guyer P, Barker D. The epidemiology of Paget's disease in Britain: is the prevalence decreasing? J Bone Miner Res. 1999; 14(2): 192-197.

31. Corral-Gudino L, Garcia-Aparicio J, Sanchez-Gonzalez MD, MironCanelo JA, Blanco JF, Ralston SH, et al. Secular changes in Paget's disease: contrasting changes in the number of new referrals and in disease severity in two neighboring regions of Spain. Osteoporos Int. 2013; 24(2): 443-450.

32. Central Statistical Office of Poland. Available from: http://stat.gov.pl/ [Accessed: 2016-11-13]

33. Abramson JH. WINPEPI updated: computer programs for epidemiologists, and their teaching potential. Epidemiologic perspectives \& innovations: EP+I. 2011; 8(1): 1.

34. Wermers RA, Tiegs RD, Atkinson EJ, Achenbach SJ, Melton LJ, 3rd. Morbidity and mortality associated with Paget's disease of bone: a population-based study. J Bone Miner Res. 2008; 23(6): 819-825.

35. Cundy HR, Gamble G, Wattie D, Rutland M, Cundy T. Paget's disease of bone in New Zealand: continued decline in disease severity. Calcif Tissue Int. 2004; 75(5): 358-364.

36. Cooper C, Harvey NC, Dennison EM, van Staa TP. Update on the epidemiology of Paget's disease of bone. J Bone Miner Res. 2006; 21 Suppl 2: 3-8.

37. Corral-Gudino L, Borao-Cengotita-Bengoa M, Del Pino-Montes J, Ralston S. Epidemiology of Paget's disease of bone: a systematic review and meta-analysis of secular changes. Bone. 2013; 55(2): 347-352.

38. Lopez-Abente G, Morales-Piga A, Bachiller-Corral FJ, Illera-Martin O, Martin-Domenech R, Abraira V. Identification of possible areas of high prevalence of Paget's disease of bone in Spain. Clin Exp Rheumatol. 2003; 21(5): 635-638.

39. Merlotti D, Gennari L, Galli B, Martini G, Calabro A, De Paola V, et al. Characteristics and familial aggregation of Paget's disease of bone in Italy. J Bone Miner Res. 2005; 20(8): 1356-1364.

40. Gennari L, Gianfrancesco F, Di Stefano M, Rendina D, Merlotti D, Esposito T, et al. SQSTM1 gene analysis and gene-environment interaction in Paget's disease of bone. J Bone Miner Res. 2010; 25(6): 1375-1384.

41. Singer FR. Paget's disease of bone-genetic and environmental factors. Nat Rev Endocrinol. 2015; 11(11): 662-671.

42. Matthews BG, Afzal MA, Minor PD, Bava U, Callon KE, Pitto RP, et al. Failure to detect measles virus ribonucleic acid in bone cells from patients with Paget's disease. J Clin Endocrinol Metab. 2008; 93(4): 1398-1401. 